\title{
The Travails of the English Language - From Obscurity to Empowerment
}

\author{
Dr. Charu Vaid \\ India \\ charuvaid@gmail.com
}

Abstract

The academic intelligentsia has been abuzz with a new found occupation-the Subaltern Studies-in the recent decades. It has drawn our attention to the outwardly quiet, but potentially volatile fault lines of our culture, which invariably run along the borders of different (and may be even irreconcilable) group interests. As he peeps in to these fissures, the watchful eye of the academic identifies many a hitherto unobserved sites of oppression; History, text, discourse, media, film, art and literature have all shed their innocent apolitical stance to emerge as sites of conflicts. Another important addition to this litany of shame is language.

Since times immemorial language has been regarded as sacred and one of the several divine bounties which makes humans human. However, language today, is more appropriately viewed as a powerfully loaded "weapon" which means service to those who wield it, and servitude to those whom it is wielded at. 
Language standardization is just one of the many areas under the gamut of linguistic problematic which concerns us today. The process of Language Standardization evokes several unpalatable adjectives like "autocratic", "tyrannical", "discriminatory" and "inequitable". On the other hand, the defense arsenal of the same term has concepts like "linguistic purity", "correct usage" etc. to give it strength.

This paper critically explores the process of the standardization of English, questioning whether or not and how this process has been linguistically oppressive. In a systematic manner, it looks at the principal stages of standardization, the prejudice at play therein, and the ideology floated to sustain the standard. By examining the fallout of linguistic exclusion on our identity, it to a less acknowledged but very significant kind of backwardness - the linguistic backwardness. Though deprivation of a social, economic and educational nature has duly been recognized and documented, linguistic dispossession can certainly do well with a little more attention. This paper, with the example provided by the standardization of English posits that the linguistic disadvantage is cause and the consequence of the socio-economic deprivation. The linguistically disadvantaged classes endure manifold curses - they are at the receiving end of an autocratic and also a linguistic hegemony. Furthermore the traumatic psychological corollary of subjugating a people's individuality, something they are doomed to endure generation after generation, is also examined. And finally in a time when the globe is shrinking and the repressed have found some hope, it asks how successful a role a standard language can play in the emancipation of the ones it once tied down. Is our Standard English Debate turning into a Standard English Paradox? 
Introduction

Fifteen hundred years ago, a timid and gawky, tribal girl reached a foreign island along with marauding bands from the cold climes of the north. She was clumsy, lean and rough, in awe of the splendor of the royal lady she saw on the island. The lady's imposing stature intimidated her and made her own lowly condition starker by comparison. If her walk was a shuffle through the lanes and byways, the lady's a sauntering glide through the boulevards. If her demeanor was casual, the lady's ceremonial. If dignity and decorum became the lady, boisterous and natural were the ways of the girl. But the wheel of time moved, calling into realization the utterly unexpected. Our young girl replaced the royal lady at the helm of affairs. The scepter had passed on into her hands. However, her pre-eminence proved to be fleeting. She had a smooth passage for a few years, but was dethroned by a new and more powerful foreigner, who was all beauty and grace. The new queen had panache, élan and exquisiteness. Her stature was tall and our girl's frail. Our girl was humbled and her ascendancy nipped in the bud. Ousted from the palace she was once again consigned to the squalor of the lower echelons. But as fate would have it, the wheel of time moved again and she once more donned the grand tiara. And this time with the determination to keep it, for eternity it seems. A feeble girl no more, she transformed into an ambitious careerist, who could not rest satisfied within the precincts of the island; she was all for expansion and aggrandizement. Riding on high seas, onboard the mercantile and missionary vessels, she reached and ruled faraway lands. And ever since, her flag continues to fly high in those lands.

This is the story of the English language. The island in the story is Britain and the two royal ladies are Latin and French. An understanding of the Standard English Debate called for a draught of history. Never has another language had the kind of experiences this 
Germanic tongue has had. Many a rags - to - riches story has been penned in English without realizing that the most inspirational of such stories is the story of English itself.

The Travails

English is one of the rare languages to have had an unbroken history of over fifteen hundred years (1500 in Britain alone); it has undergone a spectacular transformation from a little known tribal language, limited to a few thousand speakers, the very survival of which was threatened grievously at least twice, into an international language with a strong base of billions spread across all boundaries. At one time the English regretted the meager quantity of literature produced in their tongue; they apologetically stated that there were hardly any books in English, whereas stalwarts like Latin and French could boast of tomes and tomes of brilliant literature; but today its boast is that all the knowledge of the world in coded or is being codified in English.

However, there is another side to this remarkable tale and one that is not half as congratulatory as this one. It is historically well documented that so fierce is the political ambition, that it disregards its very own kith and kin. Since English arrived in Britain, it diversified along several paths, producing umpteen "Englishes"; in fact, to continue with my story, the medley of Englishes can be seen as a bevy of consanguineous sisters and cousins, all of whom were vivacious and virtuous and different and alike at the same time. Each one of them prospered in her little world and did not realise how one of their sisters was to scale dizzying heights at their expense. Little did they know that they would be stigmatised into disrepute, only to strengthen their wining sister's claim to power. And never had they suspected that not being the lingo of London and of the merchant guilds would cost them dearly. 
"...what I have most at heart, is, that some Method should be thought on for ascertaining and fixing our language for ever [...] For I am of Opinion, that it is better a language should not be wholly perfect, than that it should be perpetually changing."

- Jonathan Swift (1712)

Languages, by their very nature of creative and arbitrary usage, lend themselves to change. The factors triggering mutation in languages can be numerous ranging from genetic, anatomical to environmental, social and geographical. These cause languages to vary regionally, socially, individually and also structurally. The resultant multiplicity of languages is so immense that it threatens the very purpose of languages - communication. Thus a pressing need arises for a mechanism of language regulation, which can rise above the sea of language varieties to preserve and propagate an intelligible communication channel. A standard language is such a channel.

Stated thus, the role of a standard language seems to be not only utilitarian but also laudable and noble. But the issue of a standard language is anything but simple. All languages vary and thus all languages have a standard. However, the simplicity of the case ends if some of the extra-communicative functions of language are considered and the process of standardization are looked into.

Language does not facilitate communication alone. It serves many other ends like constructing an identity, fostering a sense of oneness and fraternity. Standard English is defined as a dialect of English with a special status. An understanding of the debatable aspects of Standard English calls for some acquaintance with how this strand of English came into being. 
The Standardization of English

Standardization of a language, according to Einar Haugen (1966), is a complicated four-stage process comprising selection, codification, elaboration of function and acceptance; these stages do not always follow a strict chronology and often overlap each other in parts.

1. Selection-From a pool of countless dialects of a language, one is chosen to bear the glorious mantle of the standard.

2. Codification-Codification of the selected dialect involves fixing its usage with regards to its linguistic features by writing books on the dialect's standard grammar, pronunciation, spellings. Codification results in a mass of books which proclaim to give the "correct" usage of the chosen dialect. What these books actually do is adopt a rigid prescriptive and authoritarian approach to language use. They proscribe most, if not all, alternative usages of the dialect. The codified form of the standard language becomes the language of the textbooks, law, education, media, legislative documents and political discourse. This codified usage then comes to be viewed at the "correct usage" and other alternative forms of putting this dialect to use are disregarded.

3. Elaboration of Function-A dialect thus chosen and codified, then spells out the area of its employment. The domain of a standard language is, more often than not, is the domain of formal discourse; it is not used in informal settings, but finds ready employment in education, government, law, commerce and media. In other words, it becomes the ceremonious language of solemn contexts. Educational institutes adhere to the standard variety most religiously; in fact textbooks, seminars and lectures propagate the standard language while the rest like the administrative and commercial organizations, sustain it.

4. Acceptance-It is important for the chosen dialect and its codified form to find acceptance in society. This can be difficult and usually recourse to an impressive but shallow ideology is taken to procure its reception. 
Selection of The East Midland Dialect as Standard

The East Midland dialect of the medieval period, a descendent of the Old English Mercian dialect, was the variety selected to be the standard. The reasons for this choice were political, commercial, economic, mercantile and even arbitrary, but by no means, linguistic. This dialect, like all other standardised dialects, did not have any intrinsic linguistic merit to qualify it to be the choice for a standard language. In fact, one of the major accomplishments of Linguistics in the twentieth century has been the demolition of the myth of the linguistic superiority of the standard dialect. This dialect was associated with medieval urban centres like Norfolk, Northamptonshire, Leicestershire, Bedfordshire and London. It derives its name from the East Midland district which was the largest of all the dialectical areas of the time. This dialect was the language of the rich merchant class based in London and also of the intellectuals of Cambridge and Oxford. The proletariat spoke the lowly Cockney dialect. The east Midland dialect also served as a kind of lingua franca among the various social groups, particularly amongst the students of the two Ivy League universities. The difference between the two was mainly of accent.

East Midland Pronunciation

[The Merchant's Pronunciation] [The Tradesman's Pronunciation] /mil/

\section{Cockney Pronunciation}

/mel/

Chaucer himself wrote in the East Midland dialect. A great surge in the reputation of this dialect was witnessed when, with the invention of Caxton's printing press, it reached government offices to become the dialect of solemn official usage. 
Acceptance of the East Midland Dialect

By the middle of the $15^{\text {th }}$ century, the chosen dialect had, by way of a tacit agreement, become the accepted language of scripted official documents. Then a lot of literature churned out from the small triangular geographic territory formed by London, Oxford and Cambridge in the $16^{\text {th }}$ century in the London variety of the East Midland dialect, explicitly established this variety as a national literary standard. These two factors polished the image of this language with a solemn sheen, reinforcing its aura with a literary and administrative formality, and won it a more or less ubiquitous acceptance. The employment of this variety in literature carried out another function of bringing some fixity to this tongue, which was rather boisterous in all its internal diversity.

Elaboration of Function of the Standard Dialect

One characteristic feature of a standard language is that it targets widest usage for itself in formal function. Standard English toppled erstwhile bigwigs Latin and French and ensconced itself in education, law, religion, literature, bureaucracy and government. Some he sternal signposts of significance in the elaboration of function of the standard:

- $\quad 1362$ - English used for the first time in law and government

- $15^{\text {th }}$ and $16^{\text {th }}$ century - Standard English became the language of education. Grammar schools mushroomed, and these under a growing secularism did away with Latin, the long time Church language, and adopted English.

- $\quad 15^{\text {th }}$ century - Protestant reformation favoured English over Latin

- $\quad 1611$ - Attempts at vernacularisation of the Bible produced the King James Bible in English; this was a feat of momentous consequences in the fields of Linguistics and Literature, not to mention Theology, politics and the general social 
life. The noteworthy linguistic result of this was the anglicanisation of British prose and speech.

- $\quad 17^{\text {th }}$ century - The first newspapers in English appeared. In fact, this century was an age of journals, prose and periodicals.

\section{Codification of The Standard}

Codification is the act of establishing a pool of accepted linguistic usage of a chosen dialect (with respect to its grammar, vocabulary, semantics and pronunciation), which is deemed the correct usage of that dialect. It is the final stage of the standardization mechanism and satisfies two conditions of -

a. Minimising formal variation.

b. While retaining ample room to functional variation.

Codification of Standard English happened in the $18^{\text {th }}$ century and was carried out by a small assembly of elite scholars. Awed by the Italian and French academies, the idea of founding their own English academies was championed by Swift, Defoe and Dryden. However, this did not materialize, and the task of the proposed assemblies was accomplished by many a regulatory language tome. Some of the books which codified Standard English are:

- Dr. Johnson's Dictionary - the single most celebrated book in standardisation process which has become synonymous with the codification of English. It codified spelling and meaning. Many good dictionaries still follow the format of this Dictionary. 
- The Rudiments of English Grammar (1761) - John Priestly

- A Short Introduction to English Grammar

Robert Loweth

- Grammatical Institutes (1763) - John Ash

- A Critical Pronouncing Dictionary (1791) - John Walker

Standard English and Social Equality

Though the Standard English Debate is like an umbrella term for many contentious issues pertaining to having one standard, the central debate within these "debates" is the relation between Standard English and social equality. Does Standard English, or for that matter any language standard, promote or curb social inequality? Is Standard English discriminatory or is it emancipatory? Does it bring people together or does it divide them? Does it assist communication or does it impede it? Arguments have been heaped up on both sides and a conclusive answer remains evasive and largely dependent on one's perspective.

Supporters of Standard English see it as a great libertarian; their argument is that by having a uniform and universal linguistic code, the Standard transcends societal and regional barriers, lets people see each other's point of view and thus promotes social equality. They also purport that Standard English by creating its own linguistic community, one which is wide enough to accommodate different people, fosters a sense of oneness. In this way it strengthens the social fabric of the community. Further they associate Standard English with discipline, morality and order. The following quotations bear testimony to this belief in Britain: 
"If you allow standards to slip to the stage where good English is no better than bad English, where people turn up filthy at school... all these things tend to cause people to have no standards at all, and once you lose standards then there is no imperative to stay out of crime."

- Norman Tebbit, MP, 1985

"Attention to the rules of grammar and care in the choice of words encourage punctiliousness in other matters...As nice points of grammar were mockingly dismissed as pedantic and irrelevant, so were punctiliousness in such matters as honesty, responsibility, property, gratitude, apology and so on."

- John Rae, The Observer, $7^{\text {th }} \quad$ Febuarary, 1982

These words quoted verbatim illustrate how Standard English, at least in Britain, is seen as a metaphor for a righteous, regulated and moral living.

Another rather ambitious claim of this lobby is that in a world burdened with differences - ethnic, social, religious, political, regional, and economic, and of gender - the only unifying factor is Standard English. It is this that keeps such disparate forces in some constructive array; it is this that communicates meaning in such a medley of diversity; it is this that acts as cohesive glue keeping the world from falling apart.

These champions see Standard English as a great leveller and contend that it frees people from being tied down into the lower stratum of the society by opening the prospects of economic prosperity to them. Equating the social with the economic, they point out that it is 
actually the non-standard which is retrograde and repressive because it affords no opportunity for any economic advancement. John Rye's statement amply favours this view when he says:

"And nothing more effectively condemns an individual to his class or ethnic ghetto than an inability to communicate clearly and logically in English. It is not a question of teaching children to 'talk posh'. It is just a question of giving them the essential tool for survival in today's society." (Evening Standard, $17^{\text {th }}$ November, 1988)

The strain running through the above quotation is one which sees Standard English to be a passport to economically rewarding jobs. And this could be a good point to turn the discussion into the opposite direction and look at what the other view is.

The critics of the Standard English ask how is it that the Standard becomes a key to lucrative jobs? They themselves answer this question by bringing to light the appropriation of all major institutional discourses by Standard English. They see an oppressive design in the very idea of a Standard English, which breeds inequality. To understand their stance, requires an understanding of how power works behind discourse.

\section{The Power behind Standard English}

Until recently, language and society were spoken of together implying some kind of a relation between them. Though it was agreed upon that language is a part of society and is influenced by it, yet the nature of this alliance has remained enigmatic. I had mostly thought of language as a sponge, which readily soaked all societal comings and goings. However, Norman Fairclough in his book Language and Power does not link the two in any way, but 
calls them one and the same. He propounds that the linguistic phenomena are special kind of social phenomena and vice versa, but they are not two separate entities linked externally. What Fairclough has done is that he has widened the compass of sociology to include the linguistic as a social process and not merely as something which records social processes, as was previously supposed. This by implication means ascribing most, but not all, societal attributes to language.

Thus sociologically, the standardization of English can be understood in terms of the demand - supply principle of Economics. It was a response to the medieval capitalistic society's economic demands. The need or "demand" for a consolidated home market towards the close of the Dark Ages began a protracted process of unification, of which the standardization of English language was only a part.

Detractors of Standard English, especially the socialists, see the standardization as a kind of linguistic hegemony perpetrated under the grand design of class dominance to further the class interests of the capitalists. They claim that the power behind Standard English is Capitalism. And as capitalism doesn't allow equitable growth, Standard English, an agent of capitalism that it is, will always favour the affluent. They claim that Standard English was prejudiced against the lower classes right from its inception and the stages of the process of standardisation amply reveal this bitter secret.

To begin with, it was the dialect of the mercantile community of London - the East Midland dialect - which was selected over all other dialects, not arbitrarily but shrewdly to maintain and propagate the capitalistic hegemony. A crafty ideology was floated to justify this selection, but twentieth century Linguistics has smashed the myth of this ideology. The very act of making a choice or selection involves rejection. And rejection is painful. This situation gets even thornier in matters of language because making choices on languages is making choices on people. I would say that the East Midland dialect was not selected, but the 
other dialects like the Kentish, Cockney, Gaelic, Welsh, north and south Midland were rejected. And when one rejects a language, one rejects people. And this is agonizing for this is oppression.

Denying a people their language is denying them a voice. The concept of "voice" can rather simply be understood as the ability or strength in a person by which he is able or unable to present his experience in a manner so as to influence the outcome of a discourse in his favour. The employment of the standard in matters legal, educational, governmental and formal provides the standard with a formidable institutional backing. Thus using nonstandards keeps its users away from the mainstream, as all the focal points of a society remain usurped by the standard. It is in this way that the selection, codification and elaboration of function of Standard English are doubly suffocating as they not only deprive people of a voice by denying equal status to non standards, but also deprive them of the contexts in which the standard is used.

The detractors also question the qualification of "the bright and shinning" to decide exclusively on language issues. They ask what the elite group of scholars had in them to qualify them to dictate on language matters and why was the standardization of English done autocratically and not democratically.

One elucidation comes in handy here. Often the issue of domination and oppression is so vehemently argued that important observations about the social moorings of the dominant power are sidelined. It is important to note that it is not always the highest social class like the royalty or clergy, which even hold the military, whose language becomes the standard. The class dominant in matters linguistic is usually the middle class and the power which has maximum say in these issues is economic and not regal, military or spiritual. This affinity between the two - economic power and linguistic concerns - is easy to understand as no 
other power leans so heavily on widespread communication for its effect as the economic power.

Ideology of Standard English

Power is dependent on ideology for its validation; it needs ideology to sponsor it and cannot have much vigor without a convincing statement of creed backing it. In fact power draws its efficacy from ideology. Following are few ideological grounds of justification which evolved simultaneously through the process of standardization of Standard English.

\section{- $\quad$ Correctness and Linguistic Purity}

This is the first ideological force floated to justify the selection and use of a small number of linguistic codes which were codified over others. It was argued that the codified forms were right and the others were wrong. It was believed, rather erroneously, that the some forms were linguistically correct and thus merited codification. That the rules of correctness of a language are socially determined and do not intrinsically arise from the language itself was only understood with the developments in the field of Linguistics in the twentieth century. Some examples can be as follows:

Standard English usage

Deemed correct

I saw it

Soap

He was a man who

didn't believe anything
Non-standard usage

Deemed incorrect

I seen it

Sope

He was a man what

didn't believe nothing. 
By declaring that only the codified forms are correct, what this ideology does is that it makes language the possession on a small number of elite users and denies other native speakers the right to their language.

\section{- $\quad$ Prestige and Stigma}

Innate linguistic correctness of a code was also taken to imply intellectual and moral superiority of its speakers and also the innate purity of code's standard dialect. And because of this, prestige was conferred upon the Standard English and its speakers. These speakers were all of the higher classes.

Hudson in Sociolinguistics defines stigma as the converse of prestige. Just as the standard codified form was considered prestigious, the non - standard dialects and their speakers were stigmatized for using "substandard varieties"- a term which has all the negative connotations of the positive adjectives used to describe the lofty standard.

- Codification and Canonization - Partners in Crime

Codification is yet another stage of the standardization process which has been severely censured for its capricious exclusion of equally worthy alternate linguistic codes of the chosen dialect. It stamped a certain number of linguistic codes with the mark of correct usage and thereby tossed others into the humiliation of incorrectness. Codification of a select corpus backed by the ideology of being linguistically perfect and accurate, won the codified forms a prestige. But, the ones which could not make it to the allegedly superior group were looked down upon and were degraded socially. However, it is not only exclusion of alternate linguistic codes which rankles with the critics. The problem widens its scope to present itself at the societal level. If we believe that the excluded codes were equally meritorious linguistically as the included ones and demand nothing more than an equal footing for them at par with the latter, then somewhere the exclusivist standards of the elite 
group are being reconciled. To concede that an alternate form should be accommodated into the selected core, because it is like the ones selected, does not tackle the issue at all. It only aggravates the concern. The detractors do not want the codified corpus to be relaxed to make room for previous also-rans, but they dispute the very grounds on which this selection is made. They question the profitability of what a society deems valuable and the social processes which fashion these values. They insist not on an expansion of the codified corpus, but on defying it. In this way the issue codification gains proximity with the issue of the canonization in Literature.

Standard English and Linguistic Inequality

Standard English is a child of subjective linguistic inequality and capitalistic interests. This inequality stems from a prejudice stained view of the languages of others. The act of living in a group, or more simply, the act of living with people around, necessitates an evaluation of them. Assessing our fellow brethren and deciding whether they are conducive to our interests or not, is entailed in the very principle of self-preservation. Being a social animal, man cannot escape being judgemental. But how this evaluation is made is truly problematic. In the absence of any strong and objective criteria to evaluate people, recourse is taken to flimsy grounds of assessment like skin colour, gender, religion and language. And these are the very fault lines along which our civilization might crumble. It cannot be argued that Standard English doesn't lead to linguistic inequality, linguistic profiling of people and circumscription or expansion of people's identities.

\section{Linguistic Profiling of People}

A very dangerous repercussion of our inability to see people neutrally is the use of language to form opinions of them. Linguistic profiling is usually prejudiced and classes 
people into high or low social stereotypes. What stereotyping does is that it encroaches upon or distorts the natural identity of a stereotyped person and this rightly causes indignation. And indignation manifests itself in numerous ways, including strife.

Literature affords many examples of prejudiced linguistic profiling of people. Most of the characters from the lower strata in Shakespeare are portrayed as boors, ruffians and buffoons. Their speech is coarse and made fun of. The Kentish dialect is the butt of many a joke in King Lear.

Standard English and Identity

Identity is a complex metaphysical concept which if plainly stated boils down to the "what" and "who" of the human self. Identity is the role a person plays in a given setting, thus it is performance or potential performance. Time and space are its primary co-ordinates and it is not a "given" but is constructed. And this construction of identity is problematic because of being relational. Another important point is that identity is always represented semiotically. In fact, identities are framed in semiotic clusters. John Blommaert in his book Discourse states that "identity is an outcome of socially conditioned semiotic work."

Semiotic representation of identity through language creates problems. Prejudiced view of a group's identity on the bases of their language degrades both the identity of the group and its language. The process of standardization of English has at every step abridged the identities of the people whose language it excluded. Standard English assumes a superior identity for those in the Standard English Culture and ascribes a lowly one to those in the realm of the non-standard culture. Identity construction through the process of language standardization has been discriminatory and hierarchical. Identities should have been constructed in a manner so as to exist in symbiotic, complementary and equal relationships, 
not in any unequal pyramid like structure. As identity is performance related, circumscription of identity is circumscription of the role a person can play in the society. It is akin to undermining his place and curtailing his space in the world. Here objection is raised at the identity ascribed by the ideology of standardization to the non-standard speakers, and the social processes that beget such biased views.

What ideology does is that it constructs language attitudes. Attitude, as Snarnoff defines it, is "a disposition to react favourably or unfavourably to a class of objects". They are culturally or socially fashioned. Zahn and Hooper list the three extremely untailored parameters of judging a language, and there by the people who use it, as its supposed superiority, social attractiveness and dynamism. It is sad, amusing, pitiable and utterly incongruous with the high intelligence levels of man that he uses criterion as inappropriate as the formal usage of a language to judge his own merit.

Wordsworth, in a different context, aptly sums up the pain and absurdity of the situation, when in Lines Written in Early Spring, he asks:

"If this belief from heaven be sent,

If such be Nature's holy plan,

Have I not reason to lament

What man has made of man?"

\section{Conclusion}

The Standard English Debate is one of the most educative and thought provoking debates of our times. These four words are not merely alphabet sequences printed on paper but are words alive and pulsating with long years of strife and tension; they encapsulate a 
history of hegemony, of the abuse of language for vested political aims, of ruthlessly stereotyped identities, of class pitted against class and also of forward progressive strides of humanity.

It is curious how a single debate can call two diagonally divergent theories of oppression and emancipation together under its compass. The word "standard" in the debate perfectly testifies this curiosity. Standard has two meanings: a kind of a benchmark or yardstick against which evaluations are made; and, something that is universal and all pervading. It is indeed intriguing how a single coinage can have two radically different insinuations as its meaning. And the peculiarity only gets further compounded when we realise that the two arms of the Standard English Debate can be seen to be extensions of the two meanings of the word "standard".

The first meaning, which has the connotations of an index of measurement, accords a high rank to Standard English and by implications, makes sub standards or second-rate vernaculars of all other languages. It is this meaning which reeks of repression. The second one, which has colors of universal acceptance, makes Standard English a great leveller, a unifying thread which runs through all the plurality of our experience. If Standard English, in the mould of the first meaning, becomes an agent of cruel conquest and sore subjugation, in the garb of the second, it undergoes quite a role reversal, becoming a great facilitator and redeemer. Perhaps, both these shades are true of the personality of Standard English.

All the charges of hegemony and oppression levied against Standard English hold water while viewing history alone. Yes, Standard English has been oppressive in the past. But even this charge weakens a bit if the urgent need of language consolidation is considered in the face of its communication defeating variety. The only prosecution which really stands, is that the standardization, should have been more democratic and its ideology more pragmatic. 
But what happens to Standard English, in our conjecture, of the times to come? With an eye on the future, Standard English is all sanguinity and hope. A link language, a universal unifying factor which strings the vast plurality of humans together. A channel which facilitates cross cultural, international, trans-oceanic communication. A language which divides no more but is the lingo of social emancipation. In a fast globalizing world which thrives on communication, Standard English is of invaluable service towards economic prosperity.

However the important question is what is Standard English today? In the present, both the past and the future coexist. Today, though the authoritarianism and stigma of Standard English have to some measure been watered down with an emphasis on being politically correct, they have not been completely supplanted by Standard English's more righteous aspirations. On the other hand, the profitability of the same has increased manifold. Nothing else serves a person more then his knowledge of Standard English today. Also, its universality has facilitated administration. Standard English, by checking the propensity of a language to go on diversifying beyond recognition into new avatars, and thus dividing the world into numerous linguistic communities, has saved communication and kept the world from falling apart.

A study of the Standard English Debate makes one wonder whether history has a way of course correcting and is time coming a full circle. For that which was once a snooty matron has transformed into a kind all-embracing mother figure. That which was once repression is today expression. Has the Standard English Debate turned into the Standard English Paradox? 


\section{Bibliography}

Blommaert, J.(2005) Discourse: A Critical Introduction. UK, Cambridge University Press

Dijk, V. (1984). Prejudice in Discourse. Amsterdam, John Benjamins Publishing Company.

Fairclough, N. (1989). Language and Power. England, Longman Group UK Ltd.

Hudson, R.A. (1996). Sociolinguistics (second edition).UK, Cambridge University Press

Llamas C., Mullany L., Stockwell P. (Eds) (2007). Routledge Campinion To

SocioLinguistics. Oxon, Routledge

Thomas L., Wareing S. (eds) (1999). Language, Society and Power An Introduction.

London, Routledge 